\title{
Repair of traumatic aortic arch to innominate vein fistula under deep hypothermia and circulatory arrest
}

\author{
D. A S T O FI, D. D I CARLO, G. D I EUSANIO, \\ and C. MAR CELLETTI \\ Department of Cardiovascular Surgery, Ospedale Cardiologico 'G. M. Lancisi' Ancona, Italy
}

\begin{abstract}
Astolfi, D., Di Carlo, D., Di Eusanio, G., and Marcelletti, C. (1976). Thorax, 31, 753-756. Repair of traumatic aortic arch to innominate vein fistula under deep hypothermia and circulatory arrest. Penetrating injuries of the thoracic aorta are usually rapidly lethal. Few patients survive for long enough to undergo surgical treatment. When penetrating injuries of the thoracic aorta are complicated by arteriovenous fistula a correct preoperative diagnosis is important for adequate planning of the surgical repair, and so selective angiography is essential. The best approach is through a median sternotomy with the use of total cardiopulmonary bypass with or without deep hypothermia and circulatory arrest. Fistulae between aorta and innominate vein invariably lead to congestive cardiac failure. A review of the literature suggests that signs of cardiac failure rarely appear early. Congestive failure developed within 30 days of the initial trauma in only two of the 12 reported cases. In our case, the early onset of cardiac failure refractory to therapy and the appearance of an expanding pulsatile mass at the base of the neck, threatening rupture, necessitated emergency surgical treatment.
\end{abstract}

Penetrating injuries of the thoracic aorta are usually rapidly lethal. Necropsy reports of 456 deaths following penetrating injuries of the heart and aorta showed that only $18 \%$ of the patients survived for longer than one hour, or long enough to undergo surgical treatment (Parmley, Mattingly, and Manion, 1958). The operative findings include isolated intra- and extrapericardial lesions of the aorta, fistulae between the aorta and the cardiac chambers, aortopulmonary artery fistula, and fistulae between the aorta and the venous system (Symbas and Sehdeva, 1970; Jeresaty, Khan, and Knight, 1972). We report the successful surgical repair of a double penetrating injury of the aortic arch associated with aorta to left innominate vein fistula and a false aneurysm in the concavity of the aortic arch.

\section{CASE REPORT}

A 48-year-old woman was referred to our institution seven days after the initial injury because of the appearance of a continuous murmur at the site of a stab wound in the right subclavian region and signs of congestive heart failure. The wound had been treated at the time by direct suture of the skin. On physical examination she had an arterial pressure of $120 / 60 \mathrm{mmHg}$ and a heart rate of $104 /$ minute. A continuous murmur was audible over the anterior upper right chest and she had marked pretibial oedema. The haematocrit was $25 \%$ and the haemoglobin $8.5 \mathrm{~g} / \mathrm{dl}$. The chest radiograph showed bilateral pleural effusions and widening of the superior mediastinum. The electrocardiogram showed sinus rhythm and signs of left ventricular overload.

The patient was initially treated with digitalis and diuretics. Two days after admission a pulsatile, expanding mass appeared above the suprasternal notch (Fig. 1). An aortogram was therefore performed, which demonstrated a massive aneurysm of the aortic arch, compressing the innominate artery, displacing the left common carotid and left subclavian arteries, and also revealed early opacification of the left innominate vein, superior vena cava, right atrium, and right ventricle (Fig. 2).

With the diagnosis of aortic arch to left innominate vein fistula the patient underwent emergency surgical treatment. 


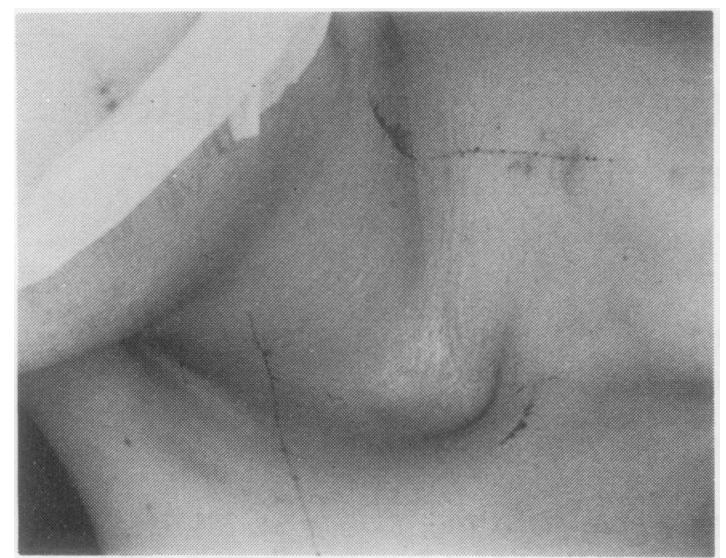

FIG. 1. The protruding pulsatile mass is located above the sternal notch.

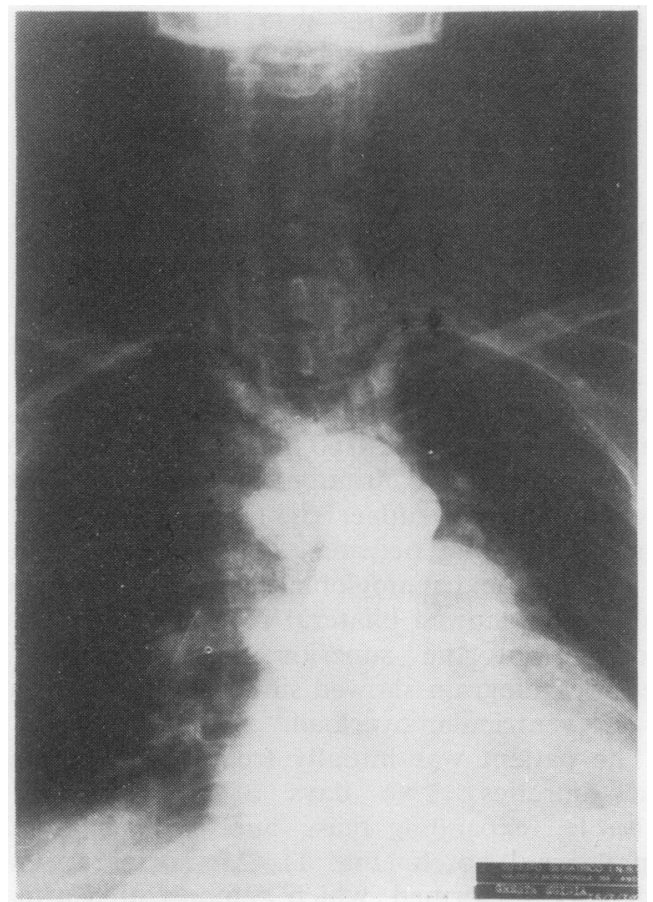

FIG. 2. Injection of contrast medium in the root of the aorta shows two false aneurysms above and to the right of the aortic arch, and the diverging innominate and left common carotid arteries. There is early opacification of the right atrium and right ventricle.

Partial cardiopulmonary bypass and core cooling were instituted by cannulating the right femoral artery and vein. A median sternotomy incision was prolonged along the anterior border of the right sternomastoid muscle.

The superior vena cava was then cannulated $\frac{\bar{F}}{\frac{5}{2}}$ and the left ventricle vented through the left $\stackrel{\mathbb{Q}}{\AA}$ atrium. The pulsatile mass, which appeared to be a false aneurysm, and the innominate vein, site $\vec{\theta}$ of a palpable thrill, were dissected free.

The heart fibrillated at $25^{\circ} \mathrm{C}$ and when the $\overrightarrow{\vec{\omega}}$ oesophageal temperature reached $21^{\circ} \mathrm{C}$ the bypass $\stackrel{\sigma}{\circ}$ was stopped.

There was a $6 \mathrm{~mm}$ laceration in the left inno- $\dot{\omega}$ minate vein, which opened into a false aneurysm, $\underset{\sigma}{\sigma}$ $4 \mathrm{~cm}$ in diameter, communicating with the aortic arch close to the origin of the left common carotid $\mathrm{\omega}$

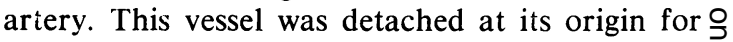
two-thirds of its circumference. An outlet stab wound was present on the postero-inferior aortic wall, communicating with a second smaller false $\stackrel{\mathbb{Q}}{\overparen{D}}$ aneurysm.

The innominate vein was divided; the posterior aortic injury was first repaired from within the $\overrightarrow{\vec{Q}}$ lumen, the origin of the left common carotid artery was reconstructed, and the anterior wall of the aorta repaired with a continuous suture.

After 60 minutes of circulatory arrest, cardiopulmonary bypass was re-established. With re-⿳亠二口犬 warming the heart defibrillated spontaneously at $25^{\circ} \mathrm{C}$. The continuity of the left innominate vein $\stackrel{\odot}{\circ}$ was restored by means of a Dacron tube.

The postoperative course was uneventful. Two days after operation anticoagulant therapy was started. Progressive reduction of the signs of congestive cardiac failure was observed. Before the patient's discharge from hospital a repeat aorto- 으 gram showed satisfactory repair of the aortic $\tilde{x}$ arch (Fig. 3). A left jugular phlebogram demon- $\frac{\dot{\sigma}}{3}$ strated thrombotic occlusion of the left innominate vein with adequate venous flow through $\delta$ collaterals such as the cervicomediastinal and $₹$ parietothoracic veins. The patient was discharged 9 26 days after operat: on without therapy.

\section{DISCUSSION}

Penetrating injuries of the thoracic aorta present $N$ with a wide pathological spectrum. In this hetero- N geneous group, fistulae between the aortic arch og and left innominate vein are a small minority. In

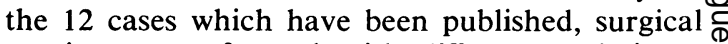
repair was performed with different techniques $\stackrel{\mathscr{P}}{-}$ and at varying intervals of time from the initial 0 trauma (Proctor, 1950; McCook, 1952; Sealy and Fawcett, 1955; Beall, Roof, and De Bakey, 1962; Conrad, Cartwright, and Mostyn, 1962; Giraud, $\mathbb{\mathbb { D }}$ 1965; Tarlov and Greenfield, 1968; Quijano Pit- $\frac{2}{2}$ 


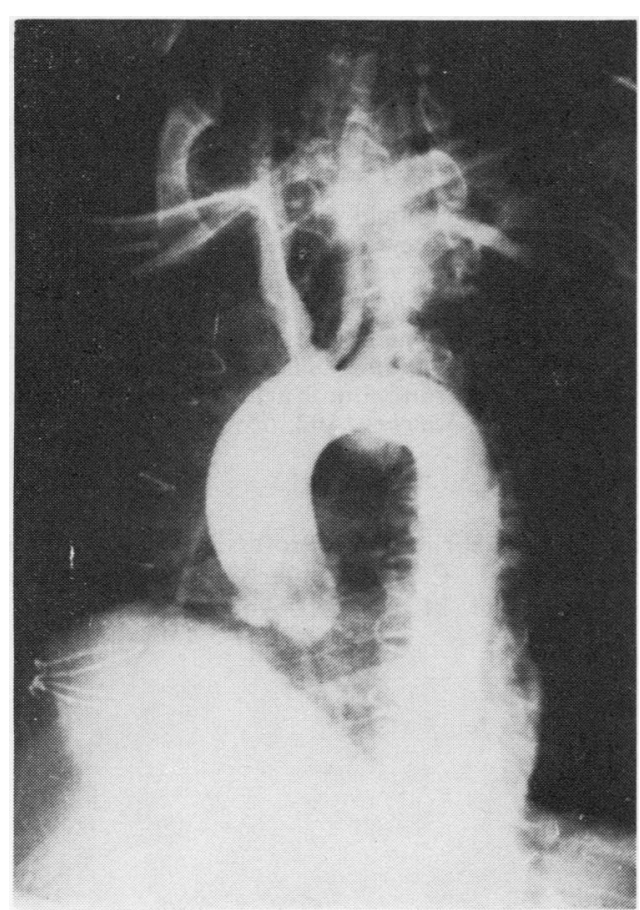

FIG. 3. Postoperative aortogram: satisfactory reconstruction of the aortic arch and origin of the left common carotid artery.

man et al., 1969; Fujise et al., 1970; Symbas and Sehdeva, 1970; Brickman et al., 1971; Treiman et al., 1971). Our patient was referred to this hospital seven days after the penetrating injury with signs of congestive heart failure and an expanding pulsatile mass in the jugular region. Most of the patients previously reported developed symptoms after a period of 2 to 20 years after the initial trauma. In two cases only was emergency surgical treatment necessary within 30 days (Treiman et al., 1971).

Surgical techniques have included direct repair of the lesion with partial clamping of the aorta, temporary bypass between the aorta and the neck vessels, and, in the presence of more complex lesions or when the preoperative diagnosis was not precise, total cardiopulmonary bypass with normothermia or deep hypothermia and circulatory arrest. The surgical approaches have varied from median sternotomy, with or without resection of the clavicle or extension of the incision above it, and uni- or bilateral thoracotomy. We believe that deep hypothermia with circula- tory arrest is essential when the site of the fistula and the presence and dimensions of a false aneurysm have not been well defined angiographically, in order to diminish the risk of uncontrollable operative haemorrhage (Borst, Schaudig, and Rudolph, 1964). In this type of case there is frequently profuse bleeding from venous collaterals under the high-pressure pulsatile flow of blood from the aorta and its branches (LeVeen and Cerruti, 1963). In our case the preoperative aortogram revealed a fistula between the aorta and the left innominate vein through a false aneurysm. The operative findings showed this diagnosis to be incomplete because we found a second aortic aneurysm on the postero-inferior wall of the arch.

The innominate vein has been dealt with by a variety of techniques, including direct repair, prosthetic replacement, or simple ligature. According to Tarlov and Greenfield (1968), the innominate vein can be safely ligated, while the risk of thrombosis and embolism seems to contraindicate the use of prosthetic material. In our case, the continuity of the innominate vein was restored by means of a Dacron tube, but the postoperative phlebogram showed complete occlusion of the prosthesis. Nevertheless even a brief period of patency might have allowed better cerebral venous drainage in the immediate postoperative period, and its gradual occlusion may have encouraged the development of the collateral circulation.

\section{REFERENCES}

Beall, A. C., Jr., Roof, W. R., and De Bakey, M. E. (1962). Successful surgical management of through-and-through stab wound of the aortic arch. Annals of Surgery, 156, 823.

Borst, H. G., Schaudig, A., and Rudolph, W. (1964). Arteriovenous fistula of the aortic arch: repair during deep hypothermia and circulatory arrest. Journal of Thoracic and Cardiovascular Surgery, 48, 443.

Brickman, R. D., Yates, A. J., Crisler, C., Schwentker, E., Bron, K., and Bahnson, H. T. (1971). Circulatory arrest during profound hypothermia: for treatment of complicated disease of major vessels. Archives of Surgery, 103, 259.

Conrad, J. K., Cartwright, R. S., and Mostyn, E. M. (1962). Arteriovenous fistula of the aortic arch. New England Journal of Medicine, 267, 15.

Fujise, Y., Nakayama, K., Inatomi, B., et al. (1970). Successfully treated case of arteriovenous fistula of the aortic arch and left brachio-cephalic vein due to trauma. (Japanese). Shujutsu, 24, 793.

Giraud, R. M. A. (1965). Arteriovenous fistula of the aortic arch complicating stab wound of the neck. South African Medical Journal, 39, 474. 
Jeresaty, R. M., Khan, A. H., and Knight, H. P. (1972). Traumatic aortico-pulmonary fistula. Cardiology (Basel), 57, 358.

LeVeen, H. H. and Cerruti, M. M. (1963). Surgery of large inaccessible arteriovenous fistulas. Annals of Surgery, 158, 285.

McCook, W. W. (1952). Arteriovenous fistula of the aortic arch. Journal of Thoracic Surgery, 23, 299.

Parmley, L. F., Mattingly, T. W., and Manion, W. C. (1958). Penetrating wounds of the heart and aorta. Circulation, 17, 953.

Proctor, W. H., Jr. (1950). Arteriovenous fistula of the aortic arch. Journal of the American Medical Association, 144, 818.

Quijano Pitman, F., Plaza Celemín, L., Naranjo Cordero, J., and Rey Domínguez, L. (1969). Fistula arteriovenosa traumática entre el cayado aórtico y el tronco venoso braquiocefálico (vena innominada). Archivos del Instituto de Cardiologia de Mexico, 39, 282.
Sealy, W. C. and Fawcett, B. (1955). Arteriovenous fistula of ascending aorta and left innominate vein. Annals of Surgery, 142, 302.

Symbas, P. N. and Sehdeva, J. S. (1970). Penetrating wounds of the thoracic aorta. Annals of Surgery, 171, 441.

Tarlov, E. and Greenfield, L. J. (1968). Post-traumatic aortic arch aneurysm with arteriovenous fistula to the innominate vein. Journal of Thoracic and Cardiovascular Surgery, 55, 134.

Treiman, R. L., Cohen, J. L., Gaspard, D. J., and Gasper, M. R. (1971). Early surgical repair of acute post-traumatic arteriovenous fistulas. Archives of Surgery, 102, 559.

Requests for reprints to: Professor Dr. D. Astolfi, 은 Department of Cardiovascular Surgery, Ospedale Cardiologico, 'G. M. Lancisi', Ancona, Italy. 